\title{
Se ThelTLAS \\ Scientists and Theologians in Front of the Mystery
}

Thierry Magnin, The Catholic University of Lyon, Bellecour 69002, Lyon, France, Email: tmagnin@univ-catholyon.fr

doi: $10.22545 / 2012 / 00030$

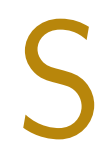
CIENCE AND THEOLOGY have their own distinct languages and modes of representing reality. These must be clearly distinguished in order to avoid naïve concordism. However, it is interesting to explore how the methods and logic used in one field can be applicable to the other, taking into account the specific constraints of each. The aim of this paper is to show how the incompleteness of both the scientist and the theologian in their own field is a new way to consider the dialog betwenne science and theology today. We will see that Christian dogmasTrinity and Incarnation, as well as the biblical notion of Covenant-can be fruitfully explored through the logic of the "included middle" as applied to quantum physics. This application of methods from one field to another emphasizes that deep, common human attitudes enable both physicists and believers to explore the nature of reality without any confusion between the fields of science and theology. Common attitudes derive from the study of the logic of the included middle and its role in science and theology. Such a field of pursuit is called "moral philosophy" because it is related to critical analysis of the ethical principles involved in comparative epistemologies in science and theology. Taking into account the different domains of science, metaphysics, and theology, we will show how moral philosophy can be a new foundation for the dialog between scientists and people of faith. Such a dialog can perhaps be helpful in promoting quality in education and in supporting peace in the modern world.

Keywords: science and technology, logic of the included middle, moral philosophy.

\section{On the Question of Reality in Science}

\subsection{General Overview}

It is now generally accepted that the development of the hard sciences in the twentieth century (in particular in the areas of mathematics and physics) has led to a reappraisal of the traditional philosophical notions of reality and meaning. In the area of the epistemology of science, the emergence of a new vision of complexity in the fields of quantum physics, thermodynamics, and cosmology has resulted in a redefinition of the word reality, perceived in scientific research as the relationship between subject and object. The observer is part of the reality that he analyzes. The theory of measurement even demonstrates that, for a physicist, to know and to measure is to act on reality. It is a "reality of interactions" that is put to scientific analysis leading to a profound re-evaluation of the three dogmas of scientism: Laplacian determinism (notions of unpredictability and uncertainty), ontological reductionism (there is more information in the whole than the sum of its parts), and methodological reductionism (undecidability and incompleteness with the Gödel theorem). 
As a result, man has become an "interpreter" of a complex world throwing into contention such notions as the strong objectivity of the sciences.

Since physicists have been confronted with the complexity of reality, scientific thinking as a whole has undergone a profound upheaval as evidenced by the demise of the Laplacian dream, "the end of certainty," or the withdrawal of foundation.

\subsection{The Demise of the Laplacian Dream}

Classical science was dominated by the notions of permanence and stability, predictions, determinism, and, ultimately, control. The idea of certainty in science was widely held and virtually synonymous with the "sharing of divine science." The development of quantum physics and non-equilibrium thermodynamics introduced the concepts of uncertainty, incompleteness and undecidability into the sphere of rationality, which radically alter the status of knowledge and the place of the knowing subject. There was a radical change in scientific thought and this had a marked effect on peoples' way of thinking in general.

Poincaré and many later scientists demonstrated that the "Laplacian dream" of determinism was an illusion. If, indeed, Newton's laws allow us to accurately predict the movements of two bodies in motion insofar as their precise trajectories are known, the same cannot be said of systems comprising three or more bodies. Complete predictability is impossible; there is no general solution to the problem. Poincaré is also responsible for the notion of unpredictability that characterizes deterministic chaos (the unpredictable behavior of a system despite the fact that it is described in terms of the equations of determinist evolution). This determinist chaos can often be seen in nature. Sensitivity to the initial conditions renders the Laplacian dream obsolete: it is not because a system is subject to a formal determinist evolutionary law that this evolution is predictable. Therefore, in respect of our current understanding, a complete description of reality cannot be conceived of. It is important, here, to emphasize a key point. By accepting to replace Laplacian determinism and the idea of certainty with determinist chaos and unpredictability, scientists opened new avenues for scientific progress. The idea of certainty seemed to be the only worthy basis on which to build a genuine scientific enterprise. However, this vision was, as it turned out, pessimistic and time (and its arrow) was just an illusion (Prigogine, [1]). Unpredictability and chaos restored the role of time, allowing it to play a constructive part in an "uncertain reality" (d'Espagnat, [2,3]). Here, the idea of probability was not introduced as a result of our ignorance but as the very result of evolution! Non-equilibrium gave us an idea of the potentialities of matter. Needless to say, then, that this change in worldview was bound to have an effect on the attitude of the scientist! For us scientists, the universe is not given-rather it is under construction!

\subsection{Something of Reality Is Beyond Our Knowledge}

Science's claims of "completeness" that go hand in hand with its claims of certainty, presuppose the existence of a language that reflects the totality of reality. Wittgenstein's studies demonstrate that the logical structures of language cannot be written within language itself (Simon, [4]). In other words, the medium in which (or thanks to which) we represent things is not representable (it cannot be expressed). There are concepts that are inexpressible outside of language. Is not the acceptance of the inexpressible a way of opening the door to the question of meaning while recognizing the contingence of man? Classical science with its dream of perfect predictability acknowledged its ambition construct a comprehensive system of representation. But Gödel's work put an end to this. His findings clearly demonstrated that there are undecidable propositions, true arithmetical propositions that cannot be deduced from axioms and truly irrefutable statements (Hosftadter, [5]). Consequently, no theory can, of its own accord, provide proof of its own consistency and that complete self-description is logically impossible. Consistency, therefore, implies incompleteness and completeness can only be obtained at the expense of consistency. Here again, what progress!

Quantum physics is prime ground for showing incompleteness, this "thing that is beyond our knowledge." Microphysics reminds us that man is not an independent spectator of the reality he explores but an integral part of it (we are "of the world," in situ). The reality described by physics is no longer independent from the terms of description. This is not only because, as we know, man developed these concepts and theories but also because to measure and to know is to have an effect on reality or, rather, to interact with it. This interaction by definition modi- 
fies the object. Consequently, each measurement is marked by an irreducible indetermination expressed, in quantum mechanical terms, by Heisenberg's uncertainty principle. This uncertainty appears, then, to be coextensive of the knowledge we derive from reality. There is a real limit to our knowledge of the quantum object. Something eludes us yet knowledge also progresses through the non passive acceptance of this incompleteness. I emphasize non passive acceptance, as Einstein's resolve to find the flaws in quantum theory (the search for hidden variables) was a contribution to the progress of knowledge.

Something is beyond our knowledge, something of the order of origins. Whether it be in the study of language (Wittgenstein), logic (Gödel), the structure of matter (Heisenberg), or irreversible evolution (Prigogine), it is apparent that similar conclusions are being arrived at regarding incompleteness, the horizon of undecidability and the impossibility of limiting truth to the totality of what can be said, whether this be formally demonstrated or directly measured. To accept that something can be formalized, is to accept that some aspect of that thing is necessarily missing. Constructing a theory of knowledge requires us to accept that something is beyond our knowledge. This does not represent a defeat of reason. Rather it is a condition of progress, of intelligibility.

The classical concepts of linear causality, reduction, completeness, and stability are replaced by those of sensitivity to the initial conditions, irreducibility, incompleteness, uncertainty, instability, and unpredictability.

Moreover, contemporary science invites us to get a measure of the positivity of this incompleteness that even appears to be a condition of knowledge. It is a good introduction to the question of the significance and the place of the subject in the exploration of the world of which it is a part! This is how scientific knowledge has progressed from certainty to uncertainty-and we reminded of the contingence and finite nature of man.

One can say that the scientism of the nineteenth century in Europe has been considerably weakened by quantum physics, which questions objectivity, Laplacian determinism, and the subject-object separability. Scientism is also weakened by the thermodynamics of irreversible processes, which questions the validity of reductionism, and also by the Gödel theorem, which considers the question of undecid- ability in mathematics. Such evolution is generally translated by the following sentence:

"Something of reality is beyond our knowledge" (Barbour, [6]).

Even if quantum physics gives new insights about reality through science, we must never forget the status of the observer in Kant's analysis. But quantum physics has generated new insights into the subject-object problem, stressing the contextuality and relationality of reality. More and more, science is shown to correspond to "the game of possibilities" as said the Nobel laureate François Jacob comparing myth and science in their relation to reality:

Mythic or scientific, the representation of
the world by man is related to his imagi-
nation. . . . To give valuable observations
in science, one must initially have in mind
some idea about what must be observed.
We need to decide before the observation
what can be observed, what is possible. A
previous idea about reality is necessary. . .
. The scientific investigation always starts
with the invention of a possible world, or
a fragment of this possible world. Mythic
thought also started in the same way. But
then Myths and Science completely differ.
(Jacob, [7])

Such an approach has been described in detail for exploring the relation between science, philosophy, and theology (Russell, Stoeger, Coyne, [8]).

\subsection{The Withdrawal of Foundation}

A characteristic of epistemological thinking today is to note what Ladrière has called "the questioning of the foundation, indeed, the withdrawal of the foundation" (Ladriére, [9]). According to Ladriére, this observation can be made through Hilbert's project to found mathematics on logical atomism and the development of phenomenology (the attempt to reconstitute the movement of the self-construction of experience).

In these three cases, the method consists in discovering a privileged region that contains the guarantees of its own validity, and showing how, through appropriate actions, it is possible to shed light on the relatively obscure parts of the discourse on experience without prejudice to the region (the role of 
foundation played by this region). Ladrière shows that Hilbert's project on the foundation of mathematics has come up against the limits of formal systems:

The demonstrations of non-contradiction (which are the main components of Hilbert's program) can only in part be relative. The idea of a privileged founding domain is untenable (both because there is no way of "reducing" everything to such a domain and because it is impossible to identify a region which would be capable of founding itself in an absolute sense) (Ladriére, [9]).

According to Ladriére, what serves as a foundation at any given moment only constitutes a temporary pause in a process that is bound to continue. These are only the contingent conditions of the research the temporary limitations of operational, conceptual, or experimental means of investigation.

There is, therefore, no essential difference between the founder (who is only ever improperly the founder) and the founded. There is no true discontinuity in their status. This signifies that this type of unshakeable solidity, this faultless consistency which was attributed to the foundation and which was transmitted to all that was founded is no longer looking so sound (Ladriére, [9]).

\subsection{Bohr's Complementarity Principle and Its Confrontation with Complexity}

The history of how Bohr's idea of complementarity has been examined by Gérard Holton (Holton, [10]). The key points of his argument are complementarity in quantum mechanics and the question of different levels of reality.

\section{Bohr's Complementarity in Quantum Mechanics}

\subsection{Presentation}

In quantum mechanics, the description of elementary particles (like the electron) that make up matter requires the use of terms that appear to be mutually exclusive and which we will call "contradictory" or "antagonistic" ( $A$ and non- $A$ ). For example, an electron is a well-recognized elementary particle whose trace and impact can be picked up by a detector (corpuscular properties). But its wave properties are just as well established and are exhibited in the phenomena of diffraction (with interferometry). To describe a particle, quantum physics refers to wave and corpuscle, even if experimentally the wave characteristic or the corpuscular characteristics are exhibited independently.

These two images of wave and corpuscle are mutually exclusive. In fact, a given entity cannot, at the same time, in our accepted usage of language be a wave (that is to say, a space that extends to a greater space) and a particle (that is a substance enclosed in a very small volume). With complementarity, however, continuity (the wave aspect) and discontinuity (corpuscular aspect) will be considered at the same time in the description of elementary particles. In this way, we find that there are numerous examples of contradictory couples (or antagonisms) in quantum mechanics: continuitydiscontinuity, separability-nonseparablity, symmetry and broken symmetry, local causality and global causality, for example. Thus a system composed of two elementary particles that is said to be entangled (both emitted by a same source for example) is said to be non separable. Nonetheless, the logic we de rive from everyday life indicates that our macroscopic world is made up of separable elements even if interactions between these elements exist and can be determined. The question is, then, how to reconcile continuity and discontinuity, macroscopic locality and microscopic locality?

Among the different approaches proposed for resolving this question, the most convincing is the principle of complementarity as expounded by the physicists Bohr and Heisenberg. They believed that complementarity describes a phenomenon by two different modes that are necessarily exclusive. It is only by considering these two contradictory modes that one can start to understand the phenomenon:

"When playing with these two images (wave/corpuscle for example), going from one to the other and then back again, we finally obtain the right impression of the strange sort of reality which hides behind our atomic experiments" (Heisenberg, [11.12]). 
Bohr and Heisenberg made use of the concept of complementarity on several occasions in order to interpret quantum theory. Hence, knowing the position of a particle is complementary to knowing its movement quantity (product of mass by velocity) If we know the value of one with a high degree of accuracy then we cannot know the value of the other with the same degree of accuracy (Heisenberg's uncertainty principle). Yet we need to know both in order to determine the behavior of this particle.

A particle can be studied experimentally with a detector or an interferometer. In other words, according to Bohr, if one wants to talk about a quantum object it is better to do so in terms of corpuscle or wave depending on the way the experiment is set up and in relation to the question asked by the observer. No image is ever complete and it is necessary to make use of two contradictory images to describe the quantum object. The change this represents, compared to classical physics, is that the very definition of the physical measurements is directly affected by the procedures and measures used:

"The measuring procedure has a fundamental influence on the conditions on which the very definition of physical quantities in question is based" (Jammer, [13]).

In this way, Bohr was able to show how in quantum mechanics the fundamental premise of the indivisibility of quantum action, forces us to adopt a new method of description that can be called complementary. Any given application of classical concepts prevents the simultaneous use of other classical concepts that in a different context are equally necessary for the elucidation of phenomena. Let us emphasize here the importance of the coupling of experimental conditions and the conceptual apparatus that forms the basis of Bohr's complementarity principle. This principle is intended to determine the manner in which those concepts work, which plays a part in the understanding of the theories of quantum phenomena-a fundamental concept for the philosophical analysis of the idea of complementarity.

This "way of viewing reality" gives rise to a paradox, at the level of language, as in the case of the wave/corpuscle, locality/nonlocality couples. However, for Bohr, the paradoxes resulting from these double descriptions are, so to speak, put to one side by the fact that it is impossible to take two simultaneous measurements of the same object, those of its wave characteristics and its corpuscular characteristics. When one of these images is materialized, the other becomes virtually or potentially realized. Let us stress, however, that this complementarity has more to do with mutually exclusive aspects of quantum phenomena than a mere juxtaposition of images. The elementary particle is neither a wave nor a corpuscle but a "thing" that combines the two images.

Even if pertinent critics on the Bohr's ideas of complementarity have been made by other founders of quantum theory (Planck, Einstein, Schrödinger and de Broglie) and by contemporary physicists and philosophers (Bohm and Feyerabend for instance), it is still of great interest for both scientists and philosophers.

\subsection{Different Levels of Reality?}

The philosopher and scientist Stéphane Lupasco and the physicist B. Nicolescu made two little-known but nonetheless major contributions to the idea of complementarity (Lupasco, $[14,15])$. Lupasco's general idea was to propose a new logic, based on what the experience of microphysics was able to say and reveal about human thought. According to him, although Hegel and Bachelard were aware of the fact that classical science was ill-suited to describe microphysical experiments, they did not go far enough. Refuting classical yes-or-no logic, Lupasco showed that that only the logic of the included middle is capable of taking into account complete reality. The diversity of reality can be structured and contained in the triad, Actualization (A)-Potentialization (P)-State (T) (which corresponds to the included third term). The actualization corresponds to that which is experimentally measured. Potentialization is that which exists "potentially" even if it is not actualized (for example, the physical states corresponding with the wave function). State $\mathrm{T}$ implies a dynamic equilibrium between A and P. Basarab Nicolescu introduced the concept of levels of reality into Lupasco's system (Nicolescu, [16]). To properly understand this concept and in order to avoid confusion with closely related concepts of levels of representation and levels of organization, we offer the following analysis.

When the physicist wants to describe a quark for example, he starts by describing it as a purely mathematical entity (this is the first level of representation), then as a free particle (the second level) and, more recently, as a particle confined in the 
hadrons (the third level). In fact, these three levels of representation belong to the same level of reality, which we shall call the quantum level. Conversely, quantons (which correspond to a particular level of representation of the elementary particles) also correspond, as we have seen, to waves and corpuscles (another level of representation). But, in this case, these two levels of representation correspond to two levels of reality, to the quantum and classical levels in physics. At the level of the organization of matter, representations are either at the same level of reality, or a combination of several levels. Thus a level of reality will correspond to a family of systems that remain invariant under the action of one law. One can distinguish different levels in according to the scales used: at the level of particles, man or planets. Moreover, two levels of reality are different if there is a break in the laws, the logic or the fundamental concepts (like causality for example) when one passes from one level to another. The following paragraph applies such concepts to the wave-particle problem.

\section{The New Logic of the included Middle in Quantum Physics}

One possible solution to this situation of apparent logical paradox is to replace the axiom of the excluded middle of classical logic-something cannot be this and also that at the same time-argued by Aristotle, by the contrary axiom of the included middle, we have the idea that there is a third term $\mathrm{T}$ that is at the same time A and non-A. As previously introduced, by the term "level" we mean a group of systems that is invariant under the action of certain laws. The passage from one level of reality to the other then involves a breakdown of laws and logic, of fundamental concepts such as causality.

In analyzing the complementarity principle, the two levels of reality that must be considered are the macroscopic level NR1 (related to classical physics with its appropriate and specific language and logic) and the microscopic level NR2 (related to quantum physics with its own appropriate and different logic). The content of the axiom of the included middle becomes clear if we put the three terms A, non-A, and $\mathrm{T}$ on a triangle diagram with the dynamics associated with them, as shown in Figure 1.

Research at point $\mathrm{T}$ corresponds to research focused on a level of reality where what is mutually exclusive at level NR1 can be unified at level NR2. It corresponds to the included middle for which point $\mathrm{T}$ is not at the same level of the contradictory logical antagonism. Notice that the antagonism is never completely solved. New antagonisms can appear from point $\mathrm{T}$ at level NR2. The figure is only a simple heuristic to represent the level structure of the included middle in quantum physics. In this representation, no basic contradictions with Aristotle's logic of non contradiction occur because point $\mathrm{T}$ is not at the same level as the two components of the basic contradiction.

Contraries, contradictions, antagonisms, and opposites are terms that have evolved since the time of Aristotle. We propose the following definition of "antagonism", both in science and (as we will see) in theology, consisting of eight charac- teristics (Kaiser, $[17]):$

- unity: the complementary modes of representation are related to the same object. What appears to be a wave under some experimental circumstances and a particle under others is in fact the same object.

- common properties: going along with the unity of the modes, in the domain appropriate to atomic phenomena, these are rest mass, electric charge and spin angular momentum.

- completeness: of each mode in one experimental situation; the object may be completely described, in a given situation, in terms of the appropriate mode without any explicit reference to the alternate mode. Only if the situation changes does the alternate mode take into account.

- co-exhaustivity: together, the two modes are sufficient to simultaneously describe the object: there is no third mode.

- equal necessity: the two modes are equally necessary, of equal importance.

- alternativity: the temporal evolution of the physical entity proceeds by a continual alternation between one mode and the other as the entity passes from one situation to another.

- co-inherence: each mode exists potentially inside the other; in this sense, the an atomic object is both a wave and a particle. There is an inter-participation or co-operation between the modes. 


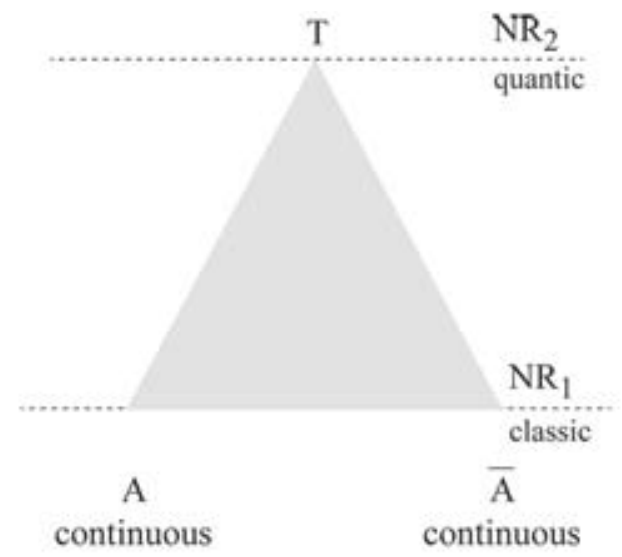

NR* $1=$ macroscopic (level 1, local causality and separability, classical physics)

NR* 2 = macroscopic (level 2, global causality and nonseparability, quantum mechanics)

$\mathrm{NR}=$ niveau de réalité (level of reality

Figure 1: Levels of reality in the logic of the included middle.

- mutual exclusivity: the two modes are mutually exclusive in the sense that they are conceptually incompatible and cannot be combined into a single picture.

\section{The Classical Logic of the Included Middle in Christian Theology: The "via Eminentiae"}

"At the end of each truth, one must consider the opposite truth, the two opposite reasons. If not, everything is heretic." (Blaise Pascal, [18])

This statement from the Christian scientistphilosopher Pascal asserts that the approach to truth requires the clash and synthetic combination of opposites. In theology, this insight has been called the "via eminentiae" based on the debate between differing views or perspectives since Thomas Aquinas.

Thus, God in the Bible is presented both as personal and non-personal, both humble and non humble-which means that He cannot be personal and humble as we imagine by simple, direct analogy to human attributes.

Indeed, one sees the formal representation of several logical antagonisms within the Christian tradition. For example, the history of the dogma of the Holy Trinity clearly shows a continuous dialectical process of searching for non-contradiction (Bertrand de Margerie, [19]). This is detailed in the Quicumque
Symbol of Athanasius (Denziger, [20]) which is a magnificient illustration to explore a unity of antagonisms, as we will see later on.

But the famous dogma of Incarnation is probably the best example of the use of the via eminentiae principle within theology. Jesus is held to be both true Man and true God, realizing on the Cross the unity of antagonisms "full power-no power." On the Cross he reveals both who is Man and who is God. Then for the disciples of Jesus, the Cross unifies the antagonisms "to become themselves [vs.] to be completely dependent and given to God." This opens a new way and power of life! One finds oneself in losing oneself !

This is not so far from Heisenberg and Bohr statement about the completely different wave-particle duality in quantum physics. As previously shown, they believed that complementarity describes a phenomenon by two different modes that are necessarily exclusive. It is only by considering these two contradictory modes that one can start to understand the phenomenon.

The question for the present analysis is to examine whether notions such as complementarity and included-middle logic used in science may be interesting for advancing the classical "via eminentiae" in theology. It will be necessary to show how such approach can be valid in theology, taking into account the specificities of each field.

In theology, a distinction separates the concepts of knowledge from revelation and knowledge from conceptual thought. For example, theologian Karl 
Rahner said:

Theology is mainly (i) the believer's explicit awareness to revelation of God in History through His Word which is Revelation per se and (ii) the scientific method in order to gain insight into His Ward as knowledge on newly acquired information. (Rahner and Vorgrimler, [21])

Thus, revelation is not separable from the experience of the community of believers in the Church in a peculiar social and cultural context. In theology, there always is "something beyond our understanding" that we call "mystery" and that is beyond the domain of logical analysis according to the empirical and logical scientific method. A mystery is not something we cannot understand. It is something we will never get to the end of (St.Augustine). A mystery is something in which the subject is involved, in contrast with an analytical problem independent of the subject. Thus, the question of the mode of representation occurs in theology as well as in science.

Kaiser [17], Barbour [6] and Reich [22] introduced the interest for theologians to use the logic of antagonisms coming from quantum physics. But they don't integrate the very useful concept of levels of reality. So, let us see now how the new logic of the included middle coming from Bohr complementarity and Lupasco and Nicolescu's interpretations can be pertinent to present the main christian dogmas.

\section{Jesus Christ, Truly God and Truly Man}

At the famous fourth ecumenical council of Chalcedoine (451 AD), the Church Fathers declared: Our lord Jesus Christ is one and the same Son...truly God and truly man...one and the same Christmade known in two natures which exist without confusion, without change, without division, without separation; the difference

Thinking in terms of complementarity, using the eight characteristics previously presented, one can observed:

- unity: the divine and human natures are united, they constitute one person (prosopon) by virtue of their conjunction (synapheia). Christ is held to be one prosopon and one hypostasis in two natures (duo physesin).

- common properties: the homoousion does double duty by asserting a common substance as well as a single being. The hypostatic union implies a single person and a common subsistence. The pre-existent subsistence of the logos is the source of the subsistence of his assumed humanity, that humanity having no independent subsistence of its own.

- completeness: each of the natures or modes of being in Christ is complete, entire, perfect and fully real in itself.

- co-exhaustivity: there are two natures or modes in Christ, no more and no less. Both modes must be included in any reasoning about the person of Christ, and neither one can be eliminated in favour of the other.

- equal necessity: the two modes are equally real and equally true and necessary.

- alternativity: since time itself is an ongoing dialectic between God and the world, the life of Christ must entail a continual alternation between its own two modes. There are two reciprocal mouvements, the deification (theosis) of the flesh and the "inhomination" (enanthropesis) of God.

- co-inherence: the logos indwells or inhabits the flesh like a garment or a temple. There follows a reciprocal penetration of the humanity into the deity of the logos so that there is a mutual penetration (perichoresis) and co-inherence between the two natures.

- mutual exclusivity: in spite of their interpenetration the two natures or modes of being remain unconfused (asunkutos) and unchanged (atreptos), each retaining its full integrity within the hypostatic union. This is due to the fact they are mutually exclusive, so that no compromise or reduction to an intermediate nature or mode is even conceivable.

It is clear in such presentation of the dialectic of the two natures of Christ that there is a specific 


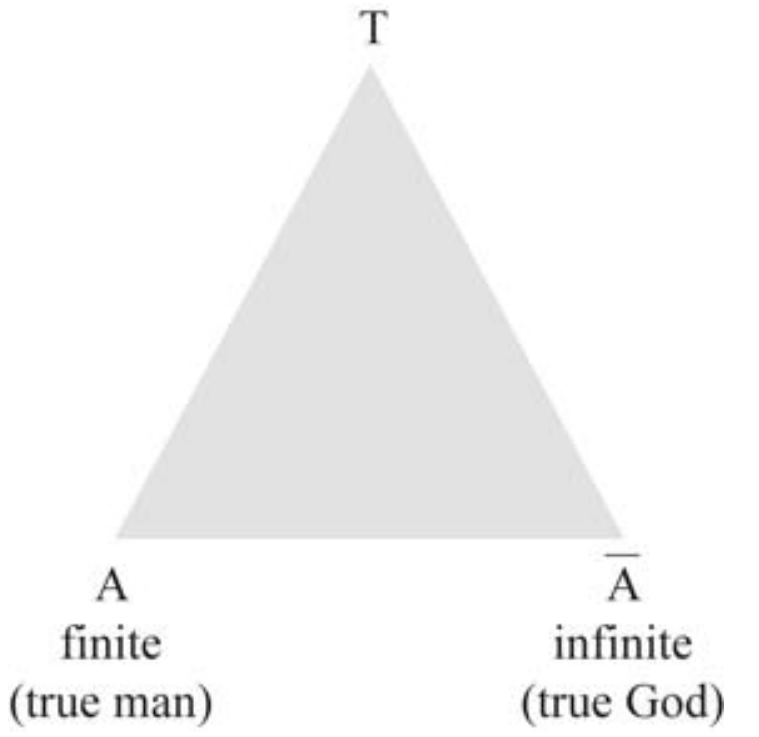

Figure 2: Representation of the dogma of incarnation in terms of levels of reality in the logic of the included middle.

coupling between experimental conditions and conceptual apparatus in theology as well as in science!

Thinking now in term of the included-middle logic, Figure 2 illustrates an analogous representation of the dogma of Incarnation in such a way, using the levels of reality.

In classical language, man is finite and God is infinite: Finite man cannot be infinite God! This statement defines reality level NR1 (bottom of triangle). In the Christian tradition, the unity of antagonisms between finite and infinite is realized by Jesus Christ, reality level NR2 (faith, top of triangle). Here, the incarnate Son of God, Christ, realizes the unity of antagonisms, particularly on the Cross (the death of eternal life). But for the believer, the Cross is still the sign of a "passing-through;" a sign of conversion that is never finished! Thus the believer goes by faith from level NRl to level NR2, but never reaches point $\mathrm{T}$. The novelty of Christ is given by revelation and is completely beyond what we can imagine.

Even if there is no relation between the status of quantum reality and the status of Jesus the Christ (obviously!), the antagonism of finite-infinite in theology in comparison with the continuous-discontinuous antagonism in science, along with their corresponding modes of representation, are quite analogous in terms of logic of the included middle. Analogy is here related to the mode of representation in terms of logic, not the attributes! The logic of quantum

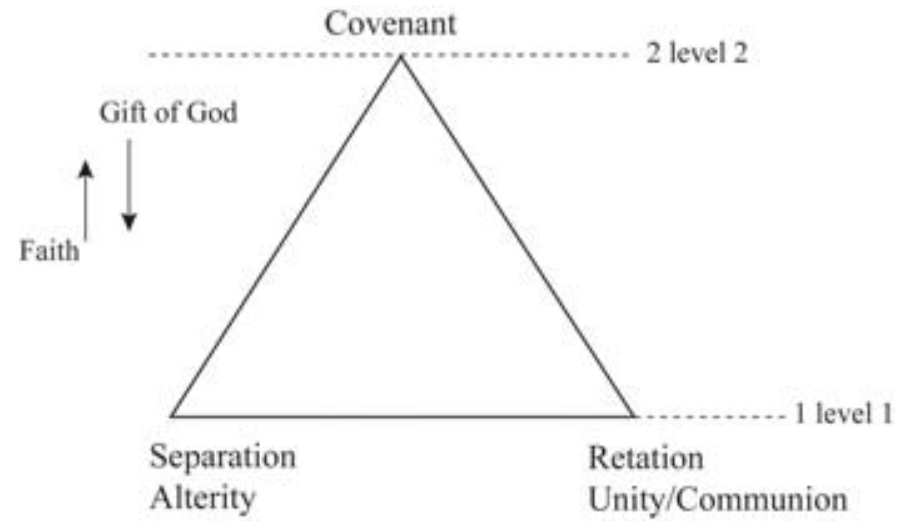

Figure 3: Representation of the biblical covenant between man and god.

physics appears quite interesting for presenting the terms of Christian dogmas and to emphasize the potential logic with respect to reality of such formally paradoxical beliefs.

\section{The Covenant in terms of Logic of the Included Middle}

Another important point of the Christian tradition, the Covenant between God and Man in the Bible, can also be expressed in terms of complementarity using the logic of the included middle.

Creation is separated from God (one of the translations of "creation" in Hebrew means "separation") and, at the same time, is in relation with God through the Covenant. Thus, the Covenant includes both the separation (alterity) and the relation (unity/communion), as shown in Figure 3.

There is a strong unity of antagonisms in the Covenant that allows both freedom of choice for man and the freely given gift of love from God to humanity. The love of God given to humanity is completely free, which is open to a free man's response. The experience of faith is open to an understanding of the Covenant as a unity of contradictions that is never completely solved by man. Using the terms from the hylemorphism of Aristotle, one can say that the actualization of the separation induces the potentialization of the relation. Similarly, the actualization of the relation induces the potentialization of the separation. This is in dynamic equilibrium.

The actualization of the separation corresponds to the usual experience of "the God's absence"! Such presentation clearly illustrates how faith corre- 
sponds to a dynamical research of God by man in a free relationship between God and man. The Bible shows a lot of historical examples of such actualization/potentialization effects.

The dynamical equilibrium corresponds to a kind of "dash" from man to God allowed by the free love of God which calls the free answer of man. In this dynamical equilibrium through the presentation with the included middle logic, the fundamental alterity between God and Creation is clear, which avoids classical forms of pantheisms.

Thus, a true partnership is proposed by God to Man in the Covenant. The free love of God allows and generates the freedom of Man. Then, the sin of Man will in fact correspond to the rupture from Man of the couple alterity-unity, for instance when Man takes the place of God or when he builds some idols. In contrast, Man can become himself inside the alterity-unity offers by the free love of God. More Man becomes Man, more God appears both intimately linked with Man and completely "Other"!

Moreover, looking to Covenant through complementarity emphasizes the fact that God creates at each moment and not only at the beginning of time and space. The love of God gives being and life to creatures at once, and not only at the beginning of the world, in space and time! This way to present Creation in Christian theology is of prior importance in the debate between science and theology.

Finally, Jesus Christ opens New Creation through Cross and Easter. On the Cross, He realizes the perfect antagonism "separation-unity" with his Father, which opens to New Covenant between God and Humanity, God and Cosmos. In the daily life, this unity of antagonisms "full power of God-non power of Christ on the Cross" corresponds to the fundamental way for Church toward the God Kingdom! Then for the Christ disciples, to become myself is closely related to give myself to God.

Thus, quantum logic can be fruitful in exploring the biblical Covenant in its specificity!

\section{The Doctrine of Trinity}

The history of the Christian dogma of the Trinity clearly shows a continuous dialectical process of searching for non-contradiction (de Margerie, [19]). In fact, the entire history of the Christian dogma of the Trinity testifies to an enormous and fruitful conflict between excluded middle thinking and in- cluded middle thinking, said the french theologian B. Sesboué (Sesboué et Meunier, [23]). We will consider as an examplary case the Quicumque Symbol, attributed to Athanasius (Denziger, [20]) and which played an important role in the development of the dogma of Trinity. Such a text cannot be read using binary classical logic.

To show the interest of the use of complementarity and of the logic of the included middle to present the doctrine of Trinity, one must develop more the notion of level of reality (for more details, see Camus, Magnin, Nicolescu, [24]).

We have previously shown that the connection between two contiguous levels is insured by the logic of the included middled and is graphically represented by a basic triangle : the contradiction (A, non-A) present at a given level of Reality, e.g., $\mathrm{NR}_{1}$ is resolved in a non-contradiction via the T-state at a immediate contiguous level, e.g., $\mathrm{NR}_{2}$ (or $\mathrm{NR}_{-2}$ ). However the "final", complete theory is not (and cannot ever be) found because in turn the respective T-state opens a new contradiction (A, non-A) at its own level, e.g., $\mathrm{NR}_{2}$ (or $\mathrm{NR}_{-2}$ ). This process continues indefinitely. The so called "Gödel-like structure of Nature and knowledge" (referring to the Godel theorem), is precisely represented by this process: the contradiction cannot be definitively solved and there is no conceivable complete theory. The logic of the included middle resolves the contradiction at a given level of Reality while simultaneously opening the contradiction at a different level of Reality.

The iterative action of the logic of the included middle, represented by the triangulation shown in Fig. 4, implies the imbrication of levels and the coherence of Nature as a whole. A particular role is played by the three topological envelopes of all $\mathrm{A}$, non-A and T-states, respectively, represented by the three closed loops in Fig. 4a.

The loops must be closed in order to insure the coherence of the transmission of information from one level to the other, in the entirety of all existing levels. Moreover, this coherence is not completely insured if the three closed loops run parallel to each other: they must join together at least at one point $\mathrm{X}$. The situation represented in Fig. 4a is only the simplest one and is therefore in no way unique: the three topological envelopes could join together at several points, say X, Y, Z, etc.

As can be verified, this text demonstrates a perfect logical coherence if one performs the following 


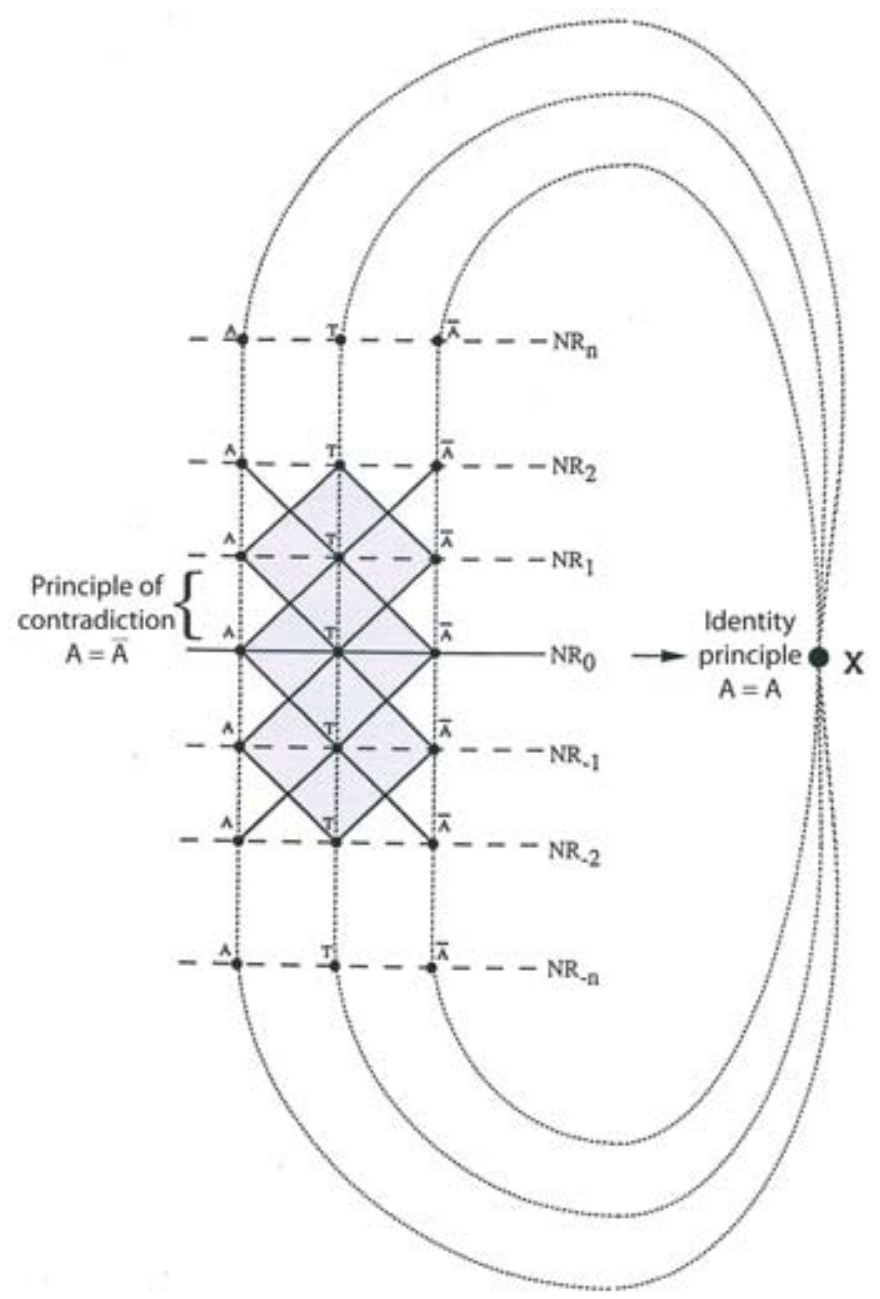

(a)

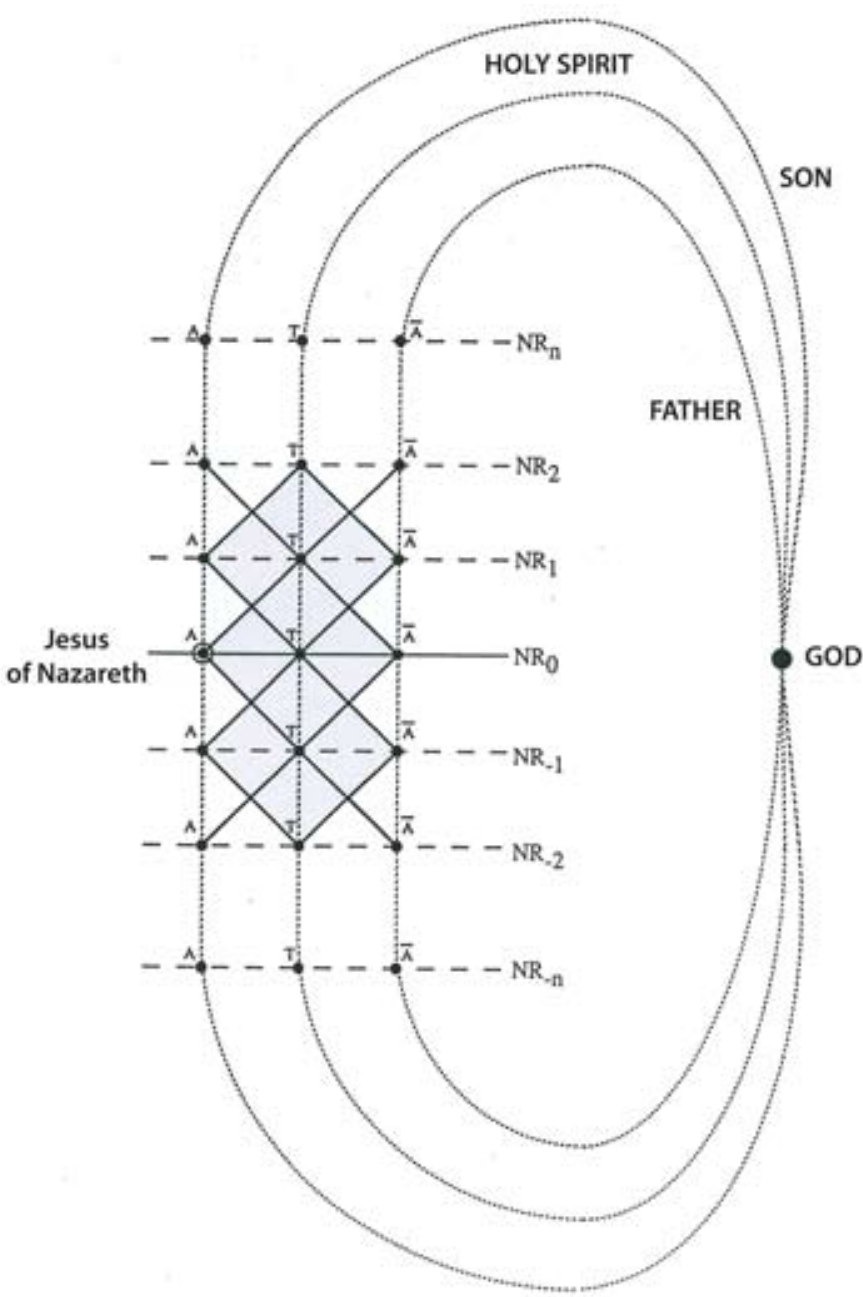

(b)

Figure 4: Graphic representation of the notion of generalized levels of reality (a) and of the Trinity Dogma in such terms (b).

correspondence at the level of language : Father $\rightarrow$ the closed loop going through all non-A (potentialization) states ; Son $\rightarrow$ the closed loop going through all A (actualization) states ; Holy Spirit $\rightarrow$ the closed loop going through all T-states ; God $\rightarrow$ point X (see Fig. 4b). For reasons of space we have limited ourselves here to only a few examples which will serve to illustrate this perfect logical coherence.

In the Quicumque symbol it is said : "Qualis $P a$ ter, talis Filius, talis Spiritus Sanctus ; increatus Pater, increatus Filius, increatus Spiritus Sanctus ; immensus Pater, immensus Filius, immensus Spiritus Sanctus ; aeternus Pater, aeternus Filius, aeternus Spiritus Sanctus : et tamen non tres aeterni, sed unus aeternus; sicut non tres increati, nec tres immensi, sed unus increatus et unus immensus..."
The word "increatus" corresponds to the right of Fig. 4b, where no levels of Reality are present. The word "immensus" corresponds to the fact that the three topological envelopes in Fig. 4b cross both the regions of "created" and "uncreated", encompassing everything which was, is and will be conceived by human reason. The word "aeternus" referes to the fact that strictly speaking, "time" is defined only in the left region of Fig. 4b, where the totality of levels of Reality is present. However, there are not three but only one "increatus", "immensus" and "aeternus", because the three closed loops in Fig. 4b join at only one point $(\mathrm{X}=\mathrm{God})$ : "et tamen non tres dei, sed unus est Deus..."

The Trinity in Fig. 4b is certainly not a hidden quaternity, in spite of the presence of point $\mathrm{X}=$ 
God. This joining (identification) point belongs to the topological definition of the three closed loops and therefore cannot be conceived as an independent entity (on the mathematical, logical or symbolic level).

Finally, let us quote an extremely significant part of the Quicumque symbol: "Pater a nullo est factus nec creatus nec genitus. Filius a Patre solo est, non factus nec creatus, sed genitus. Spiritus Sanctus a Patre et Filio non factus nec creatus nec genitus, sed procedens. Unus ergo Pater, non tres Patres, unus Filius, non tres Filii ; unus Spiritus Sanctus, non tres Spiritus Sancti; et in hac Trinitate nihil prius aut posterius, nihil maius aut minus, sed totae tres personae coaeternae sibi sunt et coaequales..."

The word "creatus", as we've already said, refers to the left part of Fig. 4b (where the levels of Reality are present), while the word "genitus" refers to the right part of Fig. 4b. However, in a dialectical process, the term "non-genitus" aquires all its meaning through the crossing of all potentialization non-A states, while "genitus" aquires all its meaning through the crossing of all actualization A-states. Finally, the word "procedens" rigorously describes the role of T-states which is that of a link of communion and love between Father and Son, in agreement with the interpretation of Saint Augustine. The role of the T-states is also in perfect agreement with what it is said about the Third in Jn 14, 16; 14, 26, where it is designated under the double aspect of "Holy Spirit" (Holy Breath) and "the other Parakletos".

Let us conclude by quoting the nice formulation of Bertrand de Margerie concerning the Trinity: "Unfathomable mystery does not contradict the rules of human logic at all" (de Margerie, [19]). Trinitarian language must remain, by definition, for ever unachieved; nevertheless, its progressive clarification is possible.

\section{Moral Philosophy: A Common Ground between Science and Religion in front of the Mystery}

According to the leitmotif of modern epistemology, in the analysis of the incompleteness of science as a whole, something is beyond our knowledge. The principle of complementarity is an interesting illustration of this. Contemporary science invites us to measure the positivity of this incompleteness, which now appears to be a very condition of knowledge. It is a good precursor to the question of the meaning and place of the subject in the exploration of the world to which it belongs. There is a withdrawal of foundation; "something is beyond our knowledge." This "absence of fixed representation" starkly highlights the questions of foundation and meaning.

The progress of scientific knowledge forces man to accept his contingency and his finiteness. This is where we touch upon moral issues. If the search for truth, in scientific, philosophical, theological, and artistic disciplines is a moral choice that could be described as innate, then running the risk of looking for this truth with a radically new logic and set of concepts could be seen as an further moral choice. We can, therefore, point to new values in the scientific method today. A critical analysis of the foundations of these values leads us to the area of moral philosophy.

\subsection{AnInitial Decision in the Scientific Method: Constructing Meaning on the Basis of Nonmeaning}

The diagram of the triangle to illustrate complementarity (with endless possibilities for new levels of comprehension of reality, since antagonism is never resolved at point $\mathrm{T}$ ), illustrates the withdrawal of foundation as already mentioned in light of the work by Ladrière. There is the "undecidability." Reason can rely on nothing but itself and, at the same time, experiences its own finiteness. Reason cannot be complete; something is beyond our knowledge.

Hence comes the initial decision of a subject: to construct meaning from nonmeaning. We have a good example of this with complementarity that aims to combine antagonisms depending on their levels of reality. This decision is an essential point in scientific reasoning as illustrated by Einstein's sentence quoted Einstein speaks of a belief that takes us into the realm of ethics. The decision to construct meaning from nonmeaning can lead to the level of ethics according to the corresponding intentionality (personal decision) according to the commitment linked to this decision.

\subsection{The Search for Meaning from Nonmeaning}

It is in the search for truth that people from different disciplines (scientists, philosophers, artists, theolo- 
gians) find themselves engaged in a moral choice that consists in finding the possibilities of meaning against what often appears to be a background of nonmeaning (the example of the importance of antagonisms). Every time thinking comes up against reality and bares its finiteness to represent it, there appears a basic dynamic for this reason that renders it capable of accepting new structures and building new concepts likely to favour progress in the intelligibility of reality. In this dynamic of reason, the choice of intelligibility of the world is central.

Moreover, as we have already seen, the conceptual means chosen to make progress in this intelligibility also constitute risky choice (for example positively accepting incompleteness, at the same time that the allure of completeness is still dominant). This reasoning has some link to the concepts of good and bad. To advocate certainty (or its opposite, uncertainty) is seen as positive or negative according to the individual. It becomes a question of moral commitment, of ethical decisions. Besides, the clashes of different schools of thought, in each discipline, serve to highlight opposing points of view that in science, for example, are of an ethical nature as well as a technical nature (see, for example, the debates on Darwinism and the theories of evolution).

In Ladrière's discussion of the dynamics of reason, he shows that it is founded on a prior ethical consideration (Ladrière, [25]). The essential is defined by the movement toward a moral life, starting from a continuous search for new representations of reality and the acceptance of their existence. Reason is seen as a representational activity, which exists to analyze and understand the world. The necessary point of departure for this reasoning is the acceptance of a fundamental otherness, constituted mainly by that which resists our representations. There are moments in scientific research when reality manifests itself in a way that shows up the inadequacy of our modes of representation. We must, therefore, accommodate this "new representation."

This "acceptance" contributes in turn to realizing the knowing subject and the good scientist. The effect of this acceptance on the subject is an important element of the moral process. It is through perceiving that which "I am not" that I become myself as a subject. This otherness is not in itself a moral value, but it corresponds to a decision-making process that involves both recognition of otherness and an inclination towards unity. It is the openness to that which is other (thing and person) that falls within the realm of ethics. A new relationship with totality is initiated; a new interaction with totality and this engenders a creative process that presupposes an openness to universality.

According to Ladrière, not only does everyone receive the totality of the universe, through their personal creativity, but this creativity itself produces a new space for communication which surpasses prior inconsistencies.
All objectivity is, therefore, the external projection of that takes place on a practi- cal plane, whereas each practical plane is crossed, in its own right, by the demands of its own externalization. When one wants to understand the dynamics of the link be- tween an objective and a practical plane, reason can, in a third instance, discover on the one hand, that in all these constituent objectivities bound only by their external constraints, the effect of its own activity as part of the process, and on the other that this activity can only find self-discovery through the objective status that it has given itself (Ladrière, [25]).

Instead of considering practical human activity as a straightforward consequence of a subconscious process to be seen in the context of time and space (moreover this activity is already an integral part of the process), the opposite is also true, according to Ladrière. The operations of this subconscious process become evident in this human activity. We therefore consider morality to be a process, whereby the otherness of a totality perceived as external, the subject interacts with and become the creator of.

Bachelard inaugurated a movement to reconcile the spirit of contradiction and scientific thought; complementary thinking expanded the movement. Pascal's statement summarizes this well: "It is necessary to have two opposing arguments. Without that there is no understanding and everything is heretical. For every truth we always remember the opposite trut" (Pascal, [18]). Bohr's treatment of the principle of complementarity shows us that the complementarity of antagonisms is a product of the activity of mind whereby the complexity of reality is rendered progressively more intelligible, with identity and otherness playing a tug of war [against a background of]. This perspective of the spirit in 
action takes on a moral dimension because it decides to create sense out of nonsense, meaning out of non meaning and derives meaning from "nonsensical" facts, and to be aware of otherness and universality.

All these points of view, based on the recognition of the unity of antagonisms (or which lead to such recognition) stem from "first-time experience," that of the link between subject and the reality to which the subject belongs, the link between the uniqueness of the subject and the multiplicity of the reality in which the subject acts. All this serves to illustrate the creative process that Ladrière talks about, Weil's position on the "search for the universal," or those of Levinas on the role of initial tension as a way of being receptive to the other (Weil, [26], Levinas, [27]). We can now discuss these points of view, which should help us to discover more about the foundations of the complementarity theory.

\subsection{Weil's State of the Search Toward Universality}

For Weil, a Kantian, strongly influenced by Hegel, there are many other perspectives from which to consider complementarity. In Logic of Philosophy, notably in the chapters "Non-Meaning," "Conditions," "Absolute," and "Work," he shows how philosophy is about a personal search for meaning in life and how it identifies the problems along the way that make this search difficult if not impossible. Weil identifies in man the finiteness of the knowing subject, incapable of comprehending reality without artificially constructing it, and his infinite liberty leading him to create a meaning through the rejection of violence seen as the refusal of a coherent discourse. Philosophy is about the making of a coherent discourse, one that makes sense, and which is based on knowledge (historical, political, economic, etc.); which have all influenced man's attitude in the past and present.

Philosophical discourse as a rejection of violence relies on a premise (the condition, our situation in the world) which may itself appear to make no sense. Weil distinguishes between discourse and language, noting that the latter falls under the heading of "the condition," (in the sense of an irreducible finiteness). It is important to insist on Weil's fundamental distinction between language and discourse. When man uses language he uses the language of a community, not the language of the "man in a specific condition." The discourse is a search for coherence that will allow the rediscovery of a universality lost in the condition. It is worth noting here that there is a problem with the scientific reasoning that sets out to describe a reality that it only has partial access to. In the process, the use of a classical language (in the case of quantum physics, for example) invariably leads to contradictions.

According to Weil, philosophical discourse is based on the premise of existence that does not appear to have any foundation and is, therefore, without meaning.

\begin{abstract}
"Inquiry shows how the manifestation of consciousness exists between meaning and non-meaning, both of which are constantly part of the discourse. For our present purposes it suffices to remember such opposites as language-condition, decision-situation, me-world. We can say that truth is a domain (condition, situation, world) and everything occupies this domain, revealing to us its existence, its non-meaning (Weil, $[26])$.
\end{abstract}

Philosophical discourse as a rejection of violence is, therefore, based on a domain (condition, situation, world) that itself becomes meaningless through the act of grasping the domain. But even before this nonmeaning of the domain can be thought of as such in philosophical discourse, it is first perceived of as an incontrovertible fact of the "the gift of life." "Lost" universality can only be rediscovered or touched through interiority and effective action. It is by such an action in the historical world that man can understand himself and, in so doing, enter a philosophical logic by looking for total coherence with the values he has recognized through thought (we find here something of the creative process described by Ladrière). It is through this process that elevation to the universal occurs, since

once the choice in favour of a coherent discourse has been made, the universal precedes the individual, not only in the transcendental sense but also in the most banal historical sense. Man is an individual first and foremost for the others he does not begin by being an individual for himself (Weil, [26]).

It is this elevation to the universal that confers value to all personal acts and which is the criteria 
for true moral philosophy for humanity. As Weil stresses, "reason is not circular." It is something that is experienced in the absence of meaning.

It is a sign of the finiteness of human knowledge, of an "incompleteness," as scientists would tend to say today. It is the action that accepts finiteness, the contingency of man, which opens the way to the universal. Underlying this process is the moral choice of coherent discourse (in this case, as a mean to reject violence).

This moral choice is not dissimilar to Einstein'sand many others'-belief that the world is intelligible! At the same time something still eludes us. The subject must derive meaning from nonmeaning, by accepting the limits of reason and rediscovering universality through an action, a positive choice; this is the basis of the complementarity and of the structure of different levels of reality we have discussed in reference to Bohr and Nicolescu. It is this elevation to the universal that confers validity on all personal action and which, according to Weil, is the only criteria for a true moral philosophy for humanity.

Weil's incisive analysis allows us to recover the distinction between the different levels on which we work. Here, it is the rejection of violence that allows us to pass from the metaphysical level (search for meaning from nonmeaning) to the level of moral philosophy (the subject finds meaning by rediscovering universality through action, a choice, in effect, which implicates him). As we have seen, this action contains an acceptance of finiteness and the contingence of man. Such "wisdom" (learn from man's contingence) provides a privileged space for dialogue with theologians (Magnin, [28]).

We have referred to the works of Weil and Ladrière in our discussion of the foundations of complementarity. This appears to be an illustration among other things of the problem of the Sameness and Otherness.

What is particularly interesting is that our approach, which started out by thinking about the current evolution of ideas in science, in fact leads us to moral philosophy by way of metaphysics (three quite different areas).

\subsection{The Meaning of Mystery}

The arguments we have presented so far can also be described in terms of a dialectic of mystery. What mystery are we referring to? It is the "mystery of knowing" that has been our theme until now, emanating from a discussion on the evolution of scientific knowledge. Einstein's assertion that "the most incomprehensible thing about the world is that it is comprehensible" and the demonstration of "fecundity" of the idea of incompleteness, are like two "signs" to the mystery of knowing in modern scientific reasoning.

One of the most interesting ways of rethinking the concept of mystery in the twentieth century was proposed by Gabriel Marcel (Marcel, [29). He criticizes philosophers for "abandoning" mystery to theologians and popularizers. Marcel not only considers the mystery of knowing but also the mystery of the union of body and soul, and the mysteries of love, hope, presence and being. In respect to the questions we are concerned with here, the most interesting aspect is the distinction he makes between problem and mystery. The problem is a question that we ask ourselves about elements that have been laid out before us, as it were, and that are, generally speaking, external to us. Of course, if we think about it we have to acknowledge that there is always the link of knowing between them and us. But characteristic of this form of thinking that considers problems is the implicit postulate that the fact of knowing does not redefine the problem. Moreover, apart from the purely intellectual interest we might have in them, there are no negative repercussions on us. The problems of classical mathematics are the most obvious example of this. There is mystery, on the contrary, when the one asking the question belongs to the very thing about which he is asking the question, that is, the mystery of being, about which I can only inquire into insofar as I am.

A mystery, is a problem which encroaches on its own data ... it is a problem that steps on its own immanent conditions of possibility. Or else: mystery is something I find myself caught up in and, I would add, not in a partial way by some predetermined or specialized aspect of myself, but on the contrary completely, since I constitute a unit which by definition can never quantify itself and which can only be an object of creation and faith (Marcel, [29]).

Mystery, therefore, breaks down the barrier between the "in me" and the "before me" which characterizes the domain of problem-solving, even if we know that the act of knowing is an intercession and that one can never attain an "in one's self." There is mystery of being that is also "the mystery of the act or of thought, which can also be translated as 
follows: we cannot ask ourselves about being as if the thinking that asks about being was outside of being." There is mystery of knowledge: "Knowledge depends on a mode of participation which no epistemology can hope to account for since it is itself the source of enquiry" (Marcel, [29]).

For Marcel, mystery is neither the unknowable nor a sort of pseudo-solution. Far from being a "knowledge gap," mystery is a call for exploration. This rehabilitation of mystery at a philosophical level (G. Marcel employs the term "meta-problematical" to describe mystery) allows for an interesting bridge with theology, as I have analyzed in my book. This is close to the approach of Saint Augustine, who said in another context, that mystery is not what one cannot understand but what one will never cease to understand.

With Marcel's view in mind, let us now return to the questions of incompleteness, complementarity and the logic of antagonisms. This is an example of the "mystery of knowing." The model relating to the concept of levels of reality expresses the mystery of knowing that the scientist is faced with. In science, we can also talk about the involvement of a thinking subject (man is a part of the nature he analyzes) even if the scientist's commitment is not as strong as the philosopher's, as defined by Marcel. We can even talk about the alteration of reality by the subject who is analyzing it even if, once again, the alteration is not as strong as in the philosophical question of being, as described by Marcel (the subject in physics is not personalized, the alteration of reality introduces itself by the measuring operations that itself is depersonalized).

Nonetheless the question of knowing in modern science refers the scientist to the mystery of knowing as so well expressed by Einstein. Hence, the search for the unity of antagonisms harks back to a "first experience" which is that of the link between the subject and the reality to which it belongs (the link between the unicity of the subject and the multiplicity of the reality in which it operates). The acceptance of the mystery of knowing is once again linked to the finiteness of man: it involves an implicit and explicit moral choice depending on the scientists! In the case of complementarity, incompleteness and the concept of the level of reality, we can talk more in terms of the "dialectics of mystery" in sciences (Marcel, [29]).

\subsection{Opening Ways to the Mystery of Man}

Twentieth-century science leads the scientist to ask about man's place in the history of the universe. This question arises out of thinking on the foundations of the major theories and the underpinnings of scientific reasoning. Classical science provided us with very mechanistic diagrams for representing the world, defining it as a large clock in which man is seen as a simple $\operatorname{cog}$ in this contraption.

We have been able to measure the influence of scientism in order to better discern what consequences the changes in perspective of contemporary science can have today on society's mentalities and ethics (Nicolescu, [16]).

"Scientific" objectivity brandished as a supreme criteria for truth, has had a far more profound effect than scientists could ever have expected. The subject has become the object (Weil, [26]). That man should be the "object" of knowledge is perfectly normal for the scientist. It is unacceptable, however, that in the name of scientism he becomes the object of exploitation, ideological experiences or scientific experiments, to be dissected, standardized, manipulated. Of course, this was not the objective of the majority of scientists who tried to establish scientific objectivity. What comes out of this is the "moral influence" that ideas and concepts that originate in science can have on society. In the sciences of the universe and matter the subject has been partially reintegrated, via the acceptance that it is linked to the object. The vision of an "uncertain world," in the words of scientists such as d'Espagnat and Prigogine, calls to go beyond scientific materialism, even if there is strong reticence among biologists.

The withdrawal of foundation discussed earlier reinforces this view. We must be careful, however, not to fill this uncertainty with a more-or-less disguised return to old certainties. The temptation to fill in the gaps of Gödel's incompleteness by a "God of the gaps" is just one example. Let us allow man to receive reality as it presents itself to us, let us give rein to reason that will be open to all eventualities, to be able to articulate the unicity of man and the multiplicity of reality. The mystery is not of the order of magic; it is of the order of intelligence that progresses without ever being self-sufficient.

Let us enter such a world. To find the meaning 
of this otherness and of this fundamental unity between the subject and reality is to make the choice in an uncertain world of positing, the possibility of an intelligibility, the existence of a meaning. To accept otherness, to avoid simplifying the complex, to think differently, this is what the scientist must choose-a moral choice, reflecting on the mystery of man in nature. In this way, fundamental moral attitudes can be called upon in all search for the truth, notably in science. We must have honesty in this search for truth, of course, acknowledgement of the foundation of meaning where human reason cannot come full circle, active acceptance of incompleteness of all knowledge and a dialectic approach whereby something will always elude us. We have to enter into an acceptance of a fundamental otherness, for the subject, (otherness looking for a link with unity), acceptance of a finiteness and of the contingence of the knowing subject and the choice of finding meaning from nonmeaning. A certain humility will result, proof of progress of knowledge that will see the abandonment of definitive certainties for an incompleteness that does not deny the search for truth but which displays our own incapacity to reach it on our own, while making us more open to the importance of this truth. All this is covered by moral philosophy! It is on this note that it is interesting to assess the relationships between the scientist and the believer in their quests.

\section{Conclusions: Related Common Attitudes between Physicists and Believers}

Consequences of the analogous use of the logic of the included middle in both theology and science are interesting in terms of human attitudes about the nature of reality. My argument seeks to avoid comparing science and theology directly. II is more important to show that the use of paradoxical complementarity by the scientist can also be an interesting application for the believer. This analogy can illuminate the depth of Christian dogmas, which many people feel must be untrue because they seem prima facie to be logical self-contradictions. However, such an analogy demonstrates common issues between scientists and theologians/believers, in completely different fields. Therefore, one can propose the following attitudes to be common through anal- ysis of included-middle logic and complementarity:

- Acceptance of reality as "reality of interactions" and as "something that resists simple representation"

- Positive acceptance of the incompleteness of our understanding of reality. Some aspects of reality are generally beyond our normal modes of understanding. Classical science used the terms "stability," "permanence," "decidability," "determinism," and "certainty" The evolution of modern science leads to considerations of "instability" of "chance," "undecidability," "unsettlement," and "uncertainty" in our knowledge. $\mathrm{R}$ is essential to see that such an evolution does not correspond to a defeat of scientific reason, but, on the contrary, a condition of progress toward a deeper conceptual understanding of reality. Nevertheless, this evolution implies a considerable change of mentality for scientists. This is similar to a challenge in ethics where acceptance of human finitude is necessary, if unwelcome. This posture of humility is also the fundamental, necessary attitude for the believer facing the mystery of God.

- Partial understanding of reality. Despite the incompleteness of our understanding, the world is partly understandable! One can then perhaps say something about God!

- Acceptance and openness to alterity through the sense that reality is deep and resists easy understanding. Reality is always partly beyond our compartmentalized representations. The same alterity is observed by the believer in theological research into God.

- Edification through confronting alterity. Moral lessons are learned in both science and theology by recognizing that we are subjects facing that which is innately beyond what we can easily confront, capture, and comprehend. Recognition of the depth and inexhaustibility of reality and the limitation of our concepts can be an important, morally potent lesson both in science and in matters of faith.

- Openness to the sense of mystery. This mystery is different in science and in theology, but is similarly significant in each (Magnin, [30]). 
In conclusion, one can say that the incompleteness of our scientific knowledge opens new ground for clarifying dialog between scientists and believers. Quantum logic can be very fruitful for presenting the ways in which some Christian dogmas are in fact addressing deep issues. It induces common human attitudes between scientists and believers, which can be of great interest for education.

\section{References}

[1] Prigogine, I. and Stengers, I., 1979. La Nouvelle Alliance, Paris, Gallimard.

[2] d'Espagnat, B., 1979. A la recherche du réel, Paris, Gauthiers-Villars.

[3] d'Espagnat, B., 1985. Une incertaine réalité, Paris, Gauthier-Villars.

[4] Simon, M., 2001. Penser et croire au temps des sciences cognitives Grenoble, Archives contemporaines.

[5] Hofstadter, D., 1985. Gödel, Escher, Bach, Paris, Interéditions.

[6] Barbour, I. G., 1997. Religion and science, San Francisco, Harper.

[7] Jacob, F., 1981. Le jeu des possibles, Paris, Flammarion.

[8] Russell, R.J., Stoeger, W.R., and Coyne, G.V., 1988. Physics, Philosophy and Theology: A common quest for understanding, Notre Dame, IN, University of Notre Dame Press.

[9] Ladriére, Jean. L'Abîme, in Savoir, faire, espérer; les limites de la raison, ed. J. Beaufret, Bruxelles: Pub. Facultés Univ. St Louis, Tome 1, 1976.

[10] Holton, G., 1991. L'imagination scientifique, Gallimard.

[11] Heisenberg, W., 1969. Der Teil und Das Ganze, Munich, Piper et Verlag.

[12] Heisenberg, W., 1972. La Partie et le Tout, Albin Michel.

[13] Jammer, M., 1974. The Philosophy of Quantum Mechanics, New York: J. Wiley and Sons.

[14] Lupasco, S., 1941. L'expérience microphysique et la pensée humaine, Paris, Le Rocher.

[15] Lupasco, S., 1986. L'homme et ses trois éthiques, Le Rocher.
[16] Nicolescu, B., 1996. La Transdisciplinarité, Le Rocher.

[17] Kaiser, C., 1974. The logic of complementarity, Edinburgh, University of Edinburgh Press.

[18] Pascal, B, 1983. Pensées, Edition de Brunschvig.

[19] Margerie (de), B., 1975 La Trinité chrétienne dans l'histoire, Paris, Beauchesne.

[20] Denziger-S., 1951. Enchiridion Symbolorum, definitionum et declarationum de rebus fidei et morum.

[21] Rahner, K., and Vorgrimler, H., 1970. Petit dictionnaire de théologie catholique Paris, Seuil.

[22] Reich, H., 1990. The relation between science and theology. Journal of Religion \& Science, 25(4), pp. 369-390.

[23] Sesboué, B., and Meunier, B., 1993. Dieu peut-il avoir un fils- le débat trinitaire du IV ème siècle, Paris, CERF.

[24] Camus, M., Magnin, T., Nicolescu, B., and Voss, K., 1994. Levels of representation and levels o reality, Munick, ESSSAT.

[25] Ladrière, J., 1993. L'éthique et la Dynamique de la Raison, in Rue Descartes No:7, Logiques de l'éthique, Albin Michel.

[26] Weil, E., 1950. Logique de la philosophie, Vrin.

[27] Levinas, E., 1971. . Totalitéet Infini, Paris, Kluwer Academic.

[28] Magnin, T., 1998. Entre science et religion, Paris, Le Rocher.

[29] Marcel, G., Positions et approches concrètes du Myst`re ontologique, Nauwelaerts et Vrin, 1949; Etre et Avoir, Paris, Aubier, 1935 ; Les Hommes contre l'humain, Paris, La Colombe, 1951.

[30] Magnin, T., 2011. L'Expérience de l'incomplétude, Lethielleux/DDB.

\section{About the Author}

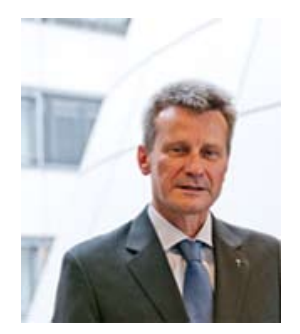


Thierry Magnin, Ph.D., Th.D., was Professor of Solid-State Physics at l'Ecole Nationale Supérieure des Mines, St. Etienne, France, and Head of the Material Science Research Laboratory (URA) at the Centre National de la Recherche Scientifique (French National Center for Scientific Research CNRS). He is now President/Rector of the Catholic Universirty of Lyon, France. He has written two hundred papers and reviews and five books on solidstate physics and won the prestigious Laureat Award of the French Academy of Sciences in 1991. Professor Magnin is also a Catholic priest and General Vicar of the diocese of St. Etienne. The topic of his thesis in theology was "The relationship between science and theology today." He has helped organize many conferences on this topic and has written four books in French (Which God for a Scientific World? Nouvelle Cité, 1993; Between Science and Religion, Le Rocher, 1998; and Scientific Parabola, Nouvelle Cité, 2000; Experience of incompleteness, Lethielleux/DDB, 2011). Professor Magnin is a Member of CIRET.

Copyright (c) 2012 by the author. This is an open access article distributed under the Creative Commons Attribution License (https://creativecommons.org/licenses/by/4.0/), which permits unrestricted use, distribution, and reproduction in any medium, provided the original work is properly cited. 